\title{
Internal Lower Incisor Morphology revealed by Computerized Microtomography
}

\author{
Carolina O. Lima', Lorena T. A. Magalhães², \\ Marília F. Marceliano-Alves' , Patrícia Y. de Oliveira ${ }^{3}$, \\ Mariane F. L. S. Lacerda² \\ ' Universidade Federal do Rio de Janeiro, Departmento de Endodontia, \\ Rio de Janeiro, Brasil. \\ 2 Universidade Federal de Juiz de Fora, Departmento de Clínica \\ Odontológica, Minas Gerais, Brasil. \\ ${ }^{3}$ Universidade Federal de Minas Gerais, Departmento de Endodontia, \\ Belo Horizonte, Minas Gerais, Brasil.
}

\begin{abstract}
This study evaluated the internal morphology of lower incisors using computerized microtomography (micro-CT) images. Eighty-nine lower incisors were scanned by micro-CT and reconstructed with NRecon software. 2D parameters (perimeter, root length, circularity and canal diameter) and $3 D$ parameters (volume, surface area and structure model index) were evaluated with CTAn and CTVol software. The results are presented descriptively. It was found that $89.9 \%$ of the canals had a single main root canal (type I), followed by type II (6.7\%) and III $(3.4 \%)$, while $5.6 \%$ of the specimens presented lateral
\end{abstract}

canals and $1.1 \%$ had an apical delta. Mean volume and surface area were $31.80 \mathrm{~mm}^{3}$ and $90.58 \mathrm{~mm}^{2}$, respectively. The most prevalent shape of the root canal at CEJ level was circular (41.6\%) and $1 \mathrm{~mm}$ from the apex, $73 \%$ of the samples were classified as oval. Lower incisors with internal anatomical variations may offer a high degree of technical complexity and may result in treatment failure.

Received: February 2020; Accepted: April 2020

Keywords: computerized microtomography, X-ray microtomography, endodontics, incisors.

\section{Morfologia interna de incisivos inferiores reveladas por microtomografía computadorizada}

\section{RESUMO}

Este estudo avaliou a morfologia interna dos dentes incisivos inferiores utilizando imagens de microtomografia computadorizada (micro-TC). 89 incisivos inferiores foram escaneados por micro-CT e reconstruidos com o programa NRecon. Parâmetros $2 D$ - perímetro, comprimento da raiz, circularidade e diâmetro do canal - e parâmetros $3 D$ - volume, área superficial e indice de modelo de estrutura - foram avaliados com os softwares CTAn e CTVol. Os resultados foram apresentados de forma descritiva. 89,9\% dos canais apresentaram um único canal radicular principal (tipo I), seguido pelo tipo II (6,7\%) e

\section{INTRODUCTION}

The root canal system (RCS) has complex internal anatomy, which needs to be clearly understood in order to ensure successful endodontic treatment. Since anatomical variations offer a high degree of technical complexity and may even result in treatment failure, the practitioner should be fully aware of both internal tooth anatomy and anatomical variations observed in daily practice ${ }^{1,2}$.
III (3,4\%). 5, 6\% dos espécimes apresentavam canais laterais e $1,1 \%$ delta apical. O volume médio e a área de superfície foram $31,80 \mathrm{~mm}^{3}$ e $90,58 \mathrm{~mm}^{2}$, respectivamente. A forma mais prevalente do canal radicular no nível da CEJ foi circular (41,6\%) e a $1 \mathrm{~mm}$ do ápice, 73\% das amostras foram classificadas como ovais. Incisivos inferiores com variações anatômicas internas podem oferecer um alto grau de complexidade técnica e resultar em falha do tratamento.

Palavras-chave: microtomografia computadorizada, microtomografia por raios- $X$, endodontia, incisivos. 
in order to ensure successful root canal treatment, more accurate imaging methods should be used to analyze internal canal morphology ${ }^{2}$.

Although computerized microtomography (micro$\mathrm{CT}$ ) is not yet available for daily clinical use, it is rapidly gaining popularity for scientific research in the field of dentistry. The micro-CT imaging method has several advantages compared to other methods, mainly because it is fast, reproducible and non-invasive, provides high-quality results which can be viewed in $2 \mathrm{D}$ and $3 \mathrm{D}$, and enables simultaneous observations of both internal and external tooth anatomy ${ }^{3}$.

In this context, the present study aims to evaluate the internal morphology of incisors using computed microtomography (micro-CT) images.

\section{MATERIALS AND METHODS}

This study was approved by the Research Ethics Committee of Federal University of Juiz de Fora (approval number 2.754.921). Forty lower central incisors and 49 lower lateral incisors were selected from the Biobank, totaling 89 teeth presenting healthy crowns and closed apices.

After cleaning the external surfaces using ultrasound (ProfiClass, Dabi Atlante Ltda. - Ribeirão Preto, SP, Brazil), the teeth were stored in universal collectors (Farmax - Distribuidora Amaral, Divinópolis, MG, Brazil) and identified. Images were acquired using a SkyScan 1173 microtomograph (Bruker MicroCT Kontich, Belgium) applying the following parameters: $50 \mathrm{Kv}, 160 \mu \mathrm{A}, 1 \mathrm{~mm}$ thickness aluminum filter with $360^{\circ}$ rotation, $0.8^{\circ}$ rotation step, pixel size $12.11 \mu \mathrm{m}$, in 2240 x 2240 (small pixel size) camera mode, totaling a scanning time of approximately 28 minutes per specimen.

Subsequently, three-dimensional (3D) specimen images were reconstructed using NRecon v1.6.6.0 software (Brucker MicroCT, Kontich, Belgium) and reduction of possible artifacts. This process resulted in an average 794 slices per specimen (range 636 to 918 slices), from the apex to the level of the cemento enamel junction, enabling internal microstructures to be viewed. The reconstructed images were then saved in bitmap format (bmp).

The following quantitative 3D parameters were evaluated: volume, root canal surface area, structure model index (SMI). When the SMI was close to 0 , the root canal was considered flat, a value close to 3 was considered cylindrical and a value close to 4 spherical ${ }^{4,5}$. The following two-dimensional (2D) parameters were assessed: perimeter, root length from cementoenamel junction (CEJ) to the apex and shape of the canal mouth, cervical, middle and apical thirds, circularity, smallest and largest anatomical canal diameter at $1 \mathrm{~mm}$ from the apex. The cross sections of the root canals were classified as round, oval or long oval according to the smaller and main canal diameter at $1 \mathrm{~mm}$ from the apex ${ }^{6}$. The $3 \mathrm{D}$ analysis plug-in and morphometric analysis tools from CTAn software were used to obtain these measurements. The presence and location of accessory canals and the amount of foramina at $4 \mathrm{~mm}$ from the apex were also evaluated.

The following anatomical parameters were evaluated using the CTAn V.1.13 and CTVol v.2.2.1 software (Bruker microCT) in the qualitative analysis: number of root canals, main root canal classification, occurrence and location of lateral root canals ${ }^{7}$, curvature degree of the main canal ${ }^{8}$, position of the anatomical foramen in relation to the apex, and presence or absence of apical constriction and its classification, when present ${ }^{9}$.

The qualitative and quantitative results of the anatomical parameters were presented descriptively, without statistical analyses.

\section{RESULTS}

The analysis of 89 human incisors indicated that $89.9 \%$ of the canals had a single main root canal and were therefore classified mostly as Vertucci type I canals. Type II (6.7\%) and type III (3.4\%) conformations were found only in lower central incisors (Fig. 1). Only 5.6\% of the specimens presented lateral root canals, $4.5 \%$ and $1.1 \%$ in the apical and middle third, respectively. However, no lateral root canal was observed in the cervical third. Only $1.1 \%$ of the sample presented an apical delta (Fig. 2).

Regarding the quantitative three-dimensional parameters, the central incisor canals had mean volume and surface area of $27.31 \pm 7.68 \mathrm{~mm}^{3}$ and $82.81 \pm 15.04 \mathrm{~mm}^{2}$, respectively. For lateral incisors, average volume was $35.88 \pm 11.11 \mathrm{~mm}^{3}$ and average surface area was $97.64 \pm 18.83 \mathrm{~mm}^{2}$. The SMI indicated that the root canal geometry of the central and lateral incisors resembled a cylinder, with SMI $=2.12 \pm 0.39$ and $1.94+0.55$, respectively.

The two-dimensional analysis results (perimeter, circularity, and largest and smallest diameter) of the 
central and lateral incisors are shown in Table 1. Root length measured from the pulp chamber to the apical foramen ranged from 11.76 to $20.84 \mathrm{~mm}$ (15; $89 \pm 1.96 \mathrm{~mm})$ and the average number of apical foramina $4 \mathrm{~mm}$ below the apex was $1.10 \pm 0.45$.

Regarding the shape of the root canal mouths at CEJ level, central incisors had prevalence of circular (58\%), followed by oval (20\%), "bowling pin" $(10 \%)$, kidney-shaped (5\%), triangular, fish and hourglass ( $3 \%$ each). In lateral incisors, prevalence was oval (35\%), followed by circular (27\%), fish and bowling pin (12\% each), triangular $(6 \%)$, kidney-shaped (4\%) and hourglass-shaped (2\%). (Fig. 3).

\section{DISCUSSION}

Knowledge of internal tooth anatomy is paramount for successful endodontic treatment ${ }^{10}$. In this context, the aim of this study was to analyze the

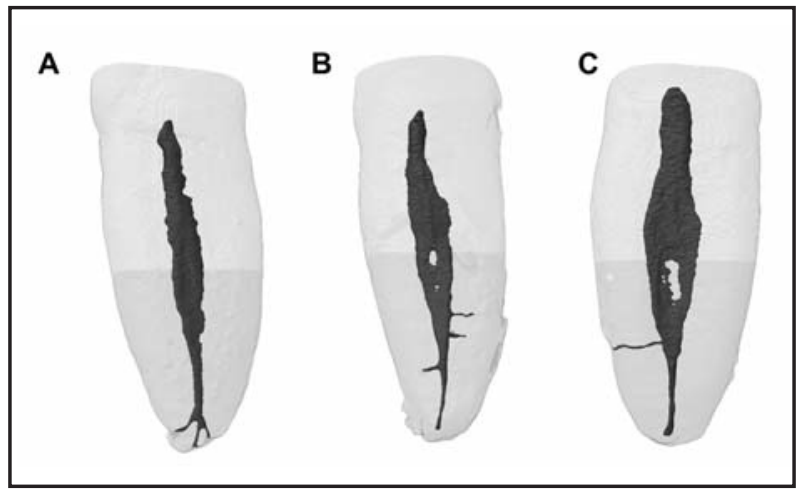

Fig. 2: Representative 3D images of A-apical delta, $B$ and $C$ lateral canals. internal morphology of mandibular and maxillary incisors by means of computed microtomography.

Several studies have reported the prevalence of a single main root canal (Vertucci Type I) in incisors, ranging from $64 \%$ to $100 \%{ }^{11-13}$. In the present study, $89.9 \%$ of the samples were classified as Vertucci type I, similar to the results reported by Lin et al. ${ }^{12}$ The divergences regarding the prevalence of a single root

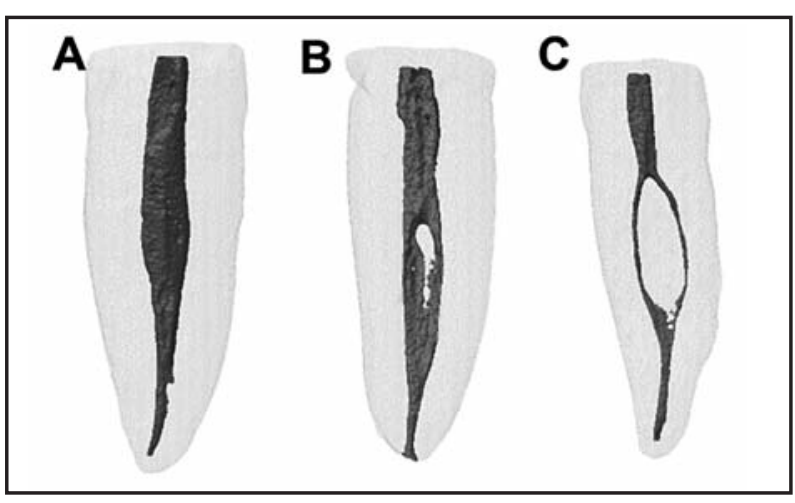

Fig. 1: Representative image of the most common main root canal classifications: A-type I, B-type II and C-type III.

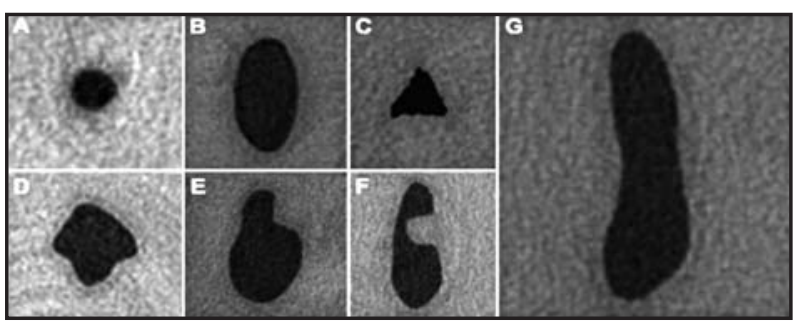

Fig. 3: Representative image of the observed cross-sections: A-circular, B-oval, C-triangular, D-fish, E- bowling pin, Fkidney-shaped and $G$-hourglass.

Table 1: 2D analysis of root canal morphology in 89 central and lateral mandibular incisors.

\begin{tabular}{|l|l|l|l|l|}
\hline & Cervical & Middle & Apical & 1mm from the apex \\
\hline Central incisors & & & & \\
\hline Perimeter $(\mathrm{mm})$ & $2.70(1.10)$ & $2.06(0.77)$ & $1.05(0.35)$ & $0.91(0.20)$ \\
\hline Circularity & $0.63(0.13)$ & $0.31(0.18)$ & $0.45(0.18)$ & $0.48(0.13)$ \\
\hline Largest diameter $(\mathrm{mm})$ & $0.95(0.35)$ & $0.94(0.37)$ & $0.38(0.19)$ & $0.36(0.11)$ \\
\hline Smallest diameter $(\mathrm{mm})$ & $0.49(0.22)$ & $0.24(0.14)$ & $0.21(0.04)$ & $0.20(0.04)$ \\
\hline Lateral incisors & & & & $0.94(0.22)$ \\
\hline Perimeter $(\mathrm{mm})$ & $3.64(1.06)$ & $2.80(0.98)$ & $1.31(0.52)$ & $0.62(0.11)$ \\
\hline Circularity & $0.49(0.12)$ & $0.26(0.17)$ & $0.43(0.18)$ & $0.35(0.09)$ \\
\hline Largest diameter $(\mathrm{mm})$ & $1.26(0.40)$ & $1.30(0.43)$ & $0.52(0.18)$ & $0.22(0.08)$ \\
\hline Smallest diameter $(\mathrm{mm})$ & $0.65(0.26)$ & $0.27(0.15)$ & $0.05)$ \\
\hline
\end{tabular}


canal in incisors can be explained due to different populations, sample size and the proposed evaluation method, such as the use of diaphanization ${ }^{11}$, cone beam computed tomography ${ }^{12,13}$ and computed microtomography ${ }^{1}$. In addition, unlike in the present study, other assessment articles do not separate central incisors from lateral incisors, which increases the range of anatomical variations compared to the current analysis, which distinguishes between different teeth.

The presence of two separate root canals that join in the apical portion (type II) and a single root canal that divides in the middle third and then joins to form a single outlet root canal (type III) accounted for $6.7 \%$ and $3.4 \%$, respectively, in lower central incisors only. These findings may be explained by the fact that a dentin bridge is formed inside the lower incisor pulp, creating two root canals within a single root, which can either merge and terminate in a single apical foramen or remain separate from each other throughout their length ${ }^{10}$.

Types IV, V, VI, VII and VIII were not observed in the current study, in agreement with previous studies $^{11-13}$. However, the aforementioned studies indicate the presence of type IV cases - two root canals separated from the crown to the apex - and/ or type $\mathrm{V}$ cases - a single root canal that divides to form two root canals in the apical region. The analysis of different populations and the evaluation methodology applied may explain these differences. Root length measured from the pulp chamber to the apical foramen ranged from 11.76 to $20.84 \mathrm{~mm}$, in agreement with the result of a previous study ${ }^{1}$. The largest and smallest root canal diameter $1 \mathrm{~mm}$ below the apex contrasts between studies, ranging from 0.13 to 1.49 (largest diameter) and 0.02-0.43 (smallest diameter) ${ }^{1,14,15}$. In the present study, the largest and smallest diameters in the apical third were, respectively, $0.38 \pm 0.19$ and $0.21 \pm 0.04$ for central incisors and $0.52 \pm 0.18$ and $0.22 . \pm 0.08$ for lateral incisors. These differences between studies may be explained by the fact that anatomical groups were separated in the present study, thereby reducing variations. By grouping upper (larger) incisors with lower (smaller) incisors, average diameter variation tends to increase.

The presence of an accessory canal, a branch that exits the main canal and communicates with the external surface of the root, an apical delta and several apical foramens enables the passage of pulp irrigants to the periodontium ${ }^{16}$ and, if not properly cleaned, may lead to endodontic treatment failure ${ }^{17}$. In the present study, only $5.6 \%$ of the specimens presented lateral canals, $4.5 \%$ and $1.1 \%$ in the apical and middle third, respectively, in agreement with findings reported in previous studies ${ }^{1,9,18}$. No lateral root canal was found in the cervical third of the teeth.

According to a previous study, only $1.1 \%$ of the sample had an apical delta, accessory canals were observed only in the apical third, and most of the central (60\%) and lateral (74\%) incisors had no accessory canals ${ }^{1}$. The average number of apical foramina $4 \mathrm{~mm}$ below the apex was $1.10 \mathrm{~mm} \pm$ $0.45 \mathrm{~mm}$.

Canals may have different cross-sectional shapes at different levels of the root in the same tooth ${ }^{15}$. In the present study, $73 \%$ of the incisors were classified as oval in the cross section $1 \mathrm{~mm}$ below the apex. In the root canal mouth at CEJ level, the most prevalent central incisor type was circular $(58 \%)$, followed by oval $(20 \%)$, while for the lateral incisors there was prevalence of oval $(35 \%)$, followed by circular (27\%).

According to the literature, mandibular incisors usually have flat and oval canals, and oval canals in this group lead to difficulties and reduce the quality of endodontic treatment ${ }^{2}$. However, although the cross-sections in the apical third and canal mouth are oval and/or circular, the SMI along the entire canal in the assessed incisors indicates that root canal geometry varies from oval to cylindrical $(\mathrm{SMI}=$ $2.02 \pm 0.49$ ), facilitating extensive endodontic canal treatment in some in canals with this characteristic. The root canal morphology of anterior teeth is variable and may present additional canals and a variety of canal configurations, as observed herein. The dentist should be aware of possible variations, as they may lead to errors in the attempt to locate root canals and, consequently, endodontic treatment failure.

Although incisors have a single root with relatively simple anatomy, internal anatomical variations may offer a high degree of technical complexity, leading to treatment failure if not well understood by dental professionals. 


\section{FUNDING}

None

\section{CORRESPONDENCE}

Dr. Patrícia Yanne de Oliveira

Universidade Federal de Minas Gerais

R. Prof. Moacir Gomes de Freitas, 688 - Pampulha

MG, 31270-901. Belo Horizonte

Minas Gerais, Brazil.

patiiioliveira@hotmail.com

9. Dummer PM, McGinn JH, Rees DG. The position and topography of the apical canal constriction and apical foramen. Int Endod J 1984; 17:192-198.

10. Assadian H, Dabbaghi A, Gooran M, Eftekhar B, Sharifi S, Shams N, Dehghani Najvani A, Tabesh H.. Accuracy of CBCT, Digital Radiography and Cross-Sectioning for the Evaluation of Mandibular Incisor Root Canals. Iran Endod J 2016; 11:106-110.

11. Rahimi S, Milani AS, Shahi S, Sergiz Y, Nezafati S, Lotfi M. Prevalence of two root canals in human mandibular anterior teeth in an Iranian population. Indian J Dent Res $2013 ; 24: 234-236$.

12. Lin Z, Hu Q, Wang T, Ge J, Liu S, Zhu M, Wen S. Use of CBCT to investigate the root canal morphology of mandibular incisors. Surg Radiol Anat 2014; 36:877-882.

13. Kamtane S, Ghodke M. Morphology of mandibular incisors: a study on CBCT. Pol J Radiol 2016; 81:15-16.

14. Mauger MJ, Schindler WG, Walker WA 3rd. An evaluation of canal morphology at different levels of root resection in mandibular incisors. J Endod 1998; 24:607-609.

15. Wu MK, R'oris A, Barkis D, Wesselink PR. Prevalence and extent of long oval canals in the apical third. Oral Surg Oral Med Oral Pathol Oral Radiol Endod 2000; 89:739-743.

16. Vertucci FJ. Root canal morphology and its relationship to endodontic procedures. Endod Top 2005; 10:3-29.

17. Siqueira JF Jr. Reaction of periradicular tissues to root canal treatment: benefits and drawbacks. Endod Top 2005; 10: 123-147.

18. Gomes BP, Rodrigues HH, Tancredo N. The use of a modelling technique to investigate the root canal morphology of mandibular incisors. Int Endod J 1996; 29: 29-36. 